\title{
Predictors of Treatments Acceptable to Patients for Late-Life Depression
}

\author{
Gerald J. Jogerst, ${ }^{1}$ Shimin Zheng, $^{2}$ and Erik Vanderlip ${ }^{1}$ \\ ${ }^{1}$ Department of Family Medicine, University of Iowa Roy J. and Lucille A. Carver College of Medicine, 200 Hawkins Drive, \\ Iowa City, IA 52242, USA \\ ${ }^{2}$ Department of Biostatistics and Epidemiology, Eastern Tennessee State University, P.O. Box 70259, Johnson City, TN 37614, USA
}

Correspondence should be addressed to Gerald J. Jogerst; gerald-jogerst@uiowa.edu

Received 7 August 2013; Accepted 2 September 2013

Academic Editors: C. Capurso and C. Mangone

Copyright (c) 2013 Gerald J. Jogerst et al. This is an open access article distributed under the Creative Commons Attribution License, which permits unrestricted use, distribution, and reproduction in any medium, provided the original work is properly cited.

Objectives. Describe older patients' perceptions about depression and characteristics associated with acceptance of treatments. Design. Cross-sectional study. Setting. Three primary care clinics in Iowa. Participants. Consecutive sample of 529 primary care patients. Measurements. Depression screening tool (a 9-item patient health questionnaire [PHQ-9]) and questionnaire including sociodemographic data, patient attitudes about depression, and acceptability of different treatments. Results. Mean age was 71.9 years (range 60-93 years), 314 (59\%) female. Among the 529 participants, 93 (17.5\%) had history of depression and 60 (11.3\%) had PHQ-9 scores of 10 or greater. Participants believed depression is a disease for which they would use medication and counseling. Accepting medications from primary physicians was strongly associated with a past history of depression $(P<0.01)$ and with agreeing that depression needs treatment $(P<0.01)$. Counseling was not acceptable for those believing that they can control depression on their own $(P<0.01)$. Older patients $(P<0.001)$ and those with higher education levels $(P<0.01)$ were less likely to accept herbs or supplements as treatment options. Willingness to discuss treatments with family was associated with not using alcohol as a treatment and acceptance of all other treatment options $(P<0.001)$. Conclusions. Attitude that depression is a disease and the willingness to discuss depression with family may enhance treatment acceptance.

\section{Introduction}

Clinically relevant depressive symptoms are present in about $20 \%$ of community-dwelling persons aged 75 years and older [1]. Late-life depression affects at least $5-10 \%$ of older primary care patients [2]. Depression often coexists with chronic medical conditions, such as dementia, Parkinson's disease, and vascular disease, and influences the prognosis of other diseases [3-5]. Depression in primary care patients aged 55 years and older has a poor prognosis [6]. Persistent depressive symptoms are associated with lower perceived health status, patient barriers to self-management [7], and higher mortality [8]. Remission of symptoms of depression is associated with reduction in mortality [9].

About $40-50 \%$ of older adults with nonpsychotic major depressive disorder (MDD) respond satisfactorily to the first prescribed antidepressant medication $[10,11]$. With vigorous and persistent treatment, up to 90 percent of older depressed patients will respond to drug therapy [12]. Within two years $60 \%$ of community-dwelling older adults with MDD became depressed again unless they were maintained on antidepressant medication [13]. Poor adherence to taking medications may account for a substantial proportion of treatment failures $[14,15]$. Patients' compliance and continuous treatment are important.

Adherence to depression treatment in late-life depression is associated with potentially modifiable factors, including patients' attitudes, beliefs, and social norms [16]. Attitudes include perceived effectiveness of treatment, preferences for types of treatment, and patient resistance to viewing depression as a medical disease $[17,18]$. Social norms including stigma of the depression diagnosis and the impact of caregivers' agreement with treatment recommendations influence treatment compliance $[16,19,20]$. 
The purpose of this study is to describe the perceptions of older ambulatory care patients about depression and characteristics associated with acceptance of various depression treatments.

\section{Materials and Methods}

2.1. Subjects. Between November 2008 and March 2009 all persons 60 years of age or older visiting one of three primary care clinics were given a packet of research materials and asked by the clinic receptionists to consider participating in the study. Two of the clinics, the Family Medicine and General Internal Medicine clinics, are located at the University of Iowa Hospitals and Clinics in Iowa City, IA. The third clinic is a free-standing primary care office in North Liberty, IA. After reading a brief cover letter explaining the research protocol, patients elected to open the packet and complete the questionnaire or to return the packet without completing the questionnaire. Seventy percent of patients who were offered participation completed the study. Age and gender distributions were similar between participants and nonparticipants. Patients who completed the questionnaire were asked to consider sharing the results of the PHQ-9 portion with their physicians during their visit.

2.2. Questionnaire. The survey instrument was four pages containing 38 large-print questions. Included were questions about demographics, religious beliefs, chronic medical problems, and a general rating of health status. Questions regarding depression included history of physiciandiagnosed depression and previous treatments used. Using a five-point Likert scale, participants were asked about their beliefs regarding depression and the treatments that would be acceptable to them if they were depressed. The questionnaire was adapted from instruments in the literature, including the ADepT questionnaire [21]. The final portion of the questionnaire was the PHQ-9 diagnostic survey [22, 23].

2.3. Consent. Capacity to consent was inferred by the participants' ability to travel to the clinic site and complete the necessary procedures to register into the clinic. If potential participants were unable to check into the clinic by themselves, their accompanying adult was given the research packet for consideration of having the elder patient participate. The project was approved by the University of Iowa Institutional Review Board.

2.4. Analysis. Descriptive statistics were obtained for all demographic and questionnaire variables. Mean differences in ratings of questionnaire items of ordinal variables were examined by $t$-test and one-way ANOVA. The chi-square test was used to examine the similarities in frequencies of categorical values. Subjects were grouped into depressed or non depressed categories by virtue of their answer to the question, "Do you have a history of depression?" PHQ-9 scores were used as a continuous variable to assess current depressive symptoms.
Stepwise linear regression method was used to identify predictors of outcome variables. Each of the seven outcome variables was regressed on variables of demographics, attitudes about depression and treatments, and circumstances influencing treatment. Variables associated with an outcome variable with a $P$ value of 0.20 or less were included as potential explanatory variables. In addition, the selected and excluded variables were checked for scientific plausibility based on past association with depressive symptoms. Using collinearity diagnostics for each final model, no strong collinearity was detected. The analysis was performed using SAS (SAS 9.2, SAS Institute, Inc., Cary, NC).

\section{Results}

The mean age of the study sample was 71.9 years; $59.4 \%$ were female, $57.1 \%$ married, and $65.7 \%$ retired. Less than $1 \%$ had no insurance, and $50 \%$ had a college or higher educational level. Self-reported health was listed as fair or poor by $19.2 \%$, and $15 \%$ of the sample had four or more chronic diseases (Table 1).

Ninety-three (17.5\%) participants had a past history of depression and were older $(P=0.05)$, had poorer selfreported health $(P=0.01)$, were more likely to be female $(13 \%$ versus $5 \%, P=0.005)$, and were likely to have had a diagnosis of heart disease or stroke ( $25 \%$ versus $16 \%, P=0.04)$. Sixty (11.3\%) had PHQ-9 scores of 10 or greater, and 134 (25\%) had PHQ-9 scores of 5 or greater.

Participants believed depression is a disease, not a part of normal aging, and requires treatment. They perceived an inability to control depression by themselves and that treatment for depression is not embarrassing (Table 2). There was general agreement by participants that they could afford treatment, and they would not decline treatment because of age, life circumstances, or other more important medical problems. There was agreement that they would discuss treatment with their family and a sense that families would want them to be treated if they were depressed (Table 2). Participants also agreed that, if they were depressed, they would use medication and counseling and follow their doctor's recommendations. They were less likely to use prayer or herbal supplements and would not consider alcohol as a treatment option (Table 3).

Depressive symptoms measured by the PHQ-9 scores were associated with the degree of agreement with statements regarding depression and treatments (Table 4). Compared to nondepressed participants, participants currently with depressive symptoms were less likely to disagree with beliefs that "depression means you are weak," "depression is a normal part of aging," "treatment for depression is embarrassing," "I could not afford treatment for depression," and "I could not travel to receive treatment for depression." Subjects with depressive symptoms were also less likely to agree to discuss treatment with family members.

In regression analyses, accepting medications from the primary physician was strongly associated with a past history of depression $(P<0.01)$ and with agreeing that depression needs treatment $(P<0.01)$ and that depression is caused by life events $(P<0.05)$. Agreement to receive medication from 
TABLE 1: Characteristics of the study sample $N=529,($ ) $=\%$.

\begin{tabular}{|c|c|}
\hline \multicolumn{2}{|l|}{ Age } \\
\hline Mean & 71.9 yrs \\
\hline Range & $60-93$ yrs \\
\hline \multicolumn{2}{|l|}{ Gender } \\
\hline Males & $(40.6)$ \\
\hline Females & $(59.4)$ \\
\hline \multicolumn{2}{|l|}{ Marital status } \\
\hline Married & $(57.1)$ \\
\hline Widowed & $(20.2)$ \\
\hline Divorced & $(15.7)$ \\
\hline Single, never married & $(5.7)$ \\
\hline Other & $(1.3)$ \\
\hline \multicolumn{2}{|l|}{ Employment status } \\
\hline Retired & $(65.7)$ \\
\hline Employed & $(21.9)$ \\
\hline Disabled & $(6.1)$ \\
\hline Homemaker & $(4.8)$ \\
\hline Unemployed & $(1.5)$ \\
\hline \multicolumn{2}{|l|}{ Education } \\
\hline$<12$ yrs & $(5.7)$ \\
\hline $12-15$ yrs & $(44.4)$ \\
\hline$\geq 16$ yrs & $(49.9)$ \\
\hline \multicolumn{2}{|c|}{ Medical visits past 3 months } \\
\hline None & $(21.9)$ \\
\hline $1-3$ & $(58.7)$ \\
\hline $4-6$ & $(13.7)$ \\
\hline$>6$ & $(5.7)$ \\
\hline \multicolumn{2}{|l|}{ Medical insurance* } \\
\hline Medicare & $(79.1)$ \\
\hline Private & $(58.9)$ \\
\hline Medicaid & $(12.6)$ \\
\hline Other & $(17.2)$ \\
\hline None & $(0.6)$ \\
\hline \multicolumn{2}{|l|}{ Religious beliefs } \\
\hline Strong & $(36.5)$ \\
\hline Average & $(41.7)$ \\
\hline Weak & $(10.6)$ \\
\hline None & $(11.2)$ \\
\hline \multicolumn{2}{|l|}{ Religious services attended } \\
\hline$>1 /$ week & $(8.8)$ \\
\hline 1/week & $(30.6)$ \\
\hline $1-2 /$ month & $(13.3)$ \\
\hline $1-2 /$ year & $(13.6)$ \\
\hline Almost never & $(33.7)$ \\
\hline \multicolumn{2}{|c|}{ Number of chronic diseases $^{+}$} \\
\hline 0 & $(17.4)$ \\
\hline 1 & $(27.3)$ \\
\hline 2 & $(26.7)$ \\
\hline 3 & $(13.5)$ \\
\hline$\geq 4$ & $(15.1)$ \\
\hline
\end{tabular}

TABLE 1: Continued.

\begin{tabular}{l}
\hline General health rating \\
Excellent \\
Very good \\
Good \\
Fair \\
$\quad$ Poor
\end{tabular}

a psychiatrist was positively related to accepting the statement that depression needs treatment $(P<0.01)$ and negatively associated with the feeling that medications would not help $(P<0.001)$. Counseling was not acceptable treatment for those believing they can control depression on their own $(P<0.01)$ or those thinking treatment was embarrassing $(P<0.001)$. Older patients $(P<0.001)$ and those with higher education levels $(P<0.01)$ are less likely to accept herbs or supplements as treatment options. Persons with greater religious belief accept prayer as a treatment $(P<0.001)$ and would not use alcohol $(P<0.001)$. Willingness to discuss treatments with family was highly associated with not using alcohol and acceptance of all other treatment options $(P<$ 0.001) (Table 5).

\section{Discussion}

Our sample exhibited a general attitude that depression is a disease physicians should ask about and is not necessarily a part of normal aging. Depression is thought to require treatment to improve, and being treated for depression is not embarrassing. These findings are similar to a nationally representative cross-sectional survey of American households showing positive mental health treatment beliefs in over $70 \%$ of persons 55 years of age or older [24]. Participants perceive that treatment is affordable, accessible and should not be avoided because of age, life circumstances, or other medical problems. These older adults would accept medication treatments for depression from their primary doctors or psychiatrists and consider counseling an acceptable intervention. This is consistent with a systematic review showing that between $49 \%$ and $84 \%$ of depressed or anxious patients perceive a need for counseling or medications [25]. As previously reported, most depressed older adults in primary care settings wish to receive some forms of treatment for their depression [26].

The types of treatments used by participants diagnosed with depression were not associated with the attitude variables. This may be due to a lack of power in the sample of 93 with past diagnoses of depression or may indicate, in persons accepting the diagnosis of depression, that attitudes do not influence treatment choices. Persons with greater depressive symptoms tended to agree or disagree in the same direction regarding the attitudes about depression as older persons without depressive symptoms. The degree of 
TABLE 2: Attitudes about depression and treatment.

\begin{tabular}{|c|c|c|c|}
\hline & $N$ & Mean* $^{*}$ & Std. dev. \\
\hline \multicolumn{4}{|l|}{ Depression } \\
\hline Depression is a kind of disease & 492 & 4.21 & 1.076 \\
\hline Depression is a personality trait & 471 & 2.62 & 1.264 \\
\hline Having depression means that the person is weak & 480 & 1.51 & .993 \\
\hline Physicians should ask patients about depression & 483 & 4.39 & 1.031 \\
\hline Depression is a normal part of aging & 483 & 2.49 & 1.265 \\
\hline Depression is caused by one's life events & 482 & 3.63 & 1.124 \\
\hline \multicolumn{4}{|l|}{ Treatment } \\
\hline Depression needs to be treated & 500 & 4.69 & .786 \\
\hline Depression improves without treatment & 479 & 2.40 & 1.222 \\
\hline Treatment for depression is embarrassing & 459 & 1.82 & 1.210 \\
\hline Taking medication will make me feel sick & 457 & 2.00 & 1.168 \\
\hline I can control depression by myself & 458 & 2.41 & 1.374 \\
\hline Medication for depression would not help me & 462 & 1.83 & 1.059 \\
\hline \multicolumn{4}{|l|}{ Circumstances influencing treatment } \\
\hline I could not afford treatment & 454 & 2.11 & 1.294 \\
\hline I would not be able to travel to the hospital or clinic to receive treatment & 451 & 1.69 & 1.173 \\
\hline My family would not agree to have me treated & 456 & 1.42 & .908 \\
\hline Because of my age, I would not want treatment & 456 & 1.47 & .970 \\
\hline Because of my life circumstances, I would not want treatment & 459 & 1.50 & 1.012 \\
\hline Because of many other more important medical problems, I would not want treatment & 453 & 1.50 & .981 \\
\hline I would discuss treatment with my family & 455 & 3.95 & 1.383 \\
\hline
\end{tabular}

${ }^{*}$ Scales 1-5, where 1 means strongly disagree, 2 means somewhat disagree, 3 means do not know, 4 means somewhat agree, and 5 means strongly agree.

TABLE 3: Treatment options.

\begin{tabular}{lccc}
\hline Statements: if I were depressed, I would & $N$ & Mean $^{*}$ & 4.35 \\
\hline Take medication prescribed by my primary physician & 466 & 4.30 & 1.145 \\
Take medication prescribed by my psychiatrist & 455 & 4.26 & 1.134 \\
Go for counseling & 462 & 4.48 & 1.135 \\
Follow my doctor's recommendations & 460 & 3.19 & .989 \\
Use prayer and meditation as a treatment & 460 & 2.63 & 1.517 \\
Take an herb or other supplement & 447 & 1.28 & 1.414 \\
Increase my alcohol intake & 455 & .773 \\
\hline
\end{tabular}

${ }^{*}$ Scales 1-5, where 1 means strongly disagree, 2 means somewhat disagree, 3 means do not know, 4 means somewhat agree, and 5 means strongly agree.

agreement, however, differed for certain statements. Persons without depressive symptoms strongly disagreed with the statements that having depression means that the person is weak and that treatment is embarrassing, whereas those with depressive symptoms only disagreed. A striking finding was in response to the willingness to discuss treatment with family members. Greater depressive symptoms were associated with less conviction that a person would discuss treatment with family. If physicians believe that it is beneficial to have family members involved in caring for depressed patients, it may be wise to encourage patients to have a family member accompany them to office visits and not to rely on patients to discuss depressive symptoms and treatment compliance issues through their own initiative.
Those who believed that depression is caused by life events had greater acceptance of antidepressants for treatment of their mood. Persons who feel that they have little intrinsic ability to impact their mood or environment are defined as having low internal locus of control and, conversely, a high external locus of control. Previous research has demonstrated an independent link between high external locus of control and depression. Our observation may reflect a desire among those with low internal locus of control to seek out treatment that depends upon as little internal change as possible [27]. Persons believing that they can control depression on their own have reduced acceptance of counseling and a greater tendency to rely on herbal supplements. Herbal supplements can be purchased without 
TABLE 4: Depressive symptoms and associations with attitudes about depression and treatment.

\begin{tabular}{|c|c|c|c|c|c|c|}
\hline Statement & PHQ-9 score & $N$ & Mean $^{*}$ & Std. dev & $F^{\dagger}$ & $P$ value \\
\hline \multirow{3}{*}{ Depression is a kind of disease } & $0-4$ & 348 & 4.27 & 1.047 & \multirow{3}{*}{3.052} & \multirow{3}{*}{.048} \\
\hline & $5-14$ & 107 & 4.03 & 1.169 & & \\
\hline & $15 \&$ up & 26 & 4.50 & .583 & & \\
\hline \multirow{3}{*}{ Having depression means that the person is weak } & $0-4$ & 338 & 1.46 & .924 & \multirow{3}{*}{6.094} & \multirow{3}{*}{.002} \\
\hline & $5-14$ & 108 & 1.54 & 1.027 & & \\
\hline & 15 \& up & 26 & 2.15 & 1.488 & & \\
\hline \multirow{3}{*}{ Depression is part of normal aging } & $0-4$ & 340 & 2.39 & 1.240 & \multirow{3}{*}{5.226} & \multirow{3}{*}{.006} \\
\hline & $5-14$ & 108 & 2.79 & 1.261 & & \\
\hline & $15 \&$ up & 25 & 2.88 & 1.301 & & \\
\hline \multirow{3}{*}{ Treatment for depression is embarrassing } & $0-4$ & 325 & 1.73 & 1.118 & \multirow{3}{*}{5.013} & \multirow{3}{*}{.007} \\
\hline & 5-14 & 103 & 2.09 & 1.380 & & \\
\hline & $15 \&$ up & 24 & 2.25 & 1.511 & & \\
\hline \multirow{3}{*}{ I could not afford treatment } & $0-4$ & 324 & 1.98 & 1.202 & \multirow{3}{*}{7.288} & \multirow{3}{*}{.001} \\
\hline & $5-14$ & 100 & 2.47 & 1.473 & & \\
\hline & $15 \&$ up & 24 & 2.58 & 1.442 & & \\
\hline \multirow{3}{*}{$\begin{array}{l}\text { I would not be able to travel to the hospital or clinic to } \\
\text { receive treatment }\end{array}$} & $0-4$ & 321 & 1.58 & 1.073 & \multirow{3}{*}{6.031} & \multirow{3}{*}{.003} \\
\hline & $5-14$ & 101 & 1.95 & 1.374 & & \\
\hline & $15 \&$ up & 23 & 2.17 & 1.403 & & \\
\hline \multirow{3}{*}{ Because of my age, I would not want treatment } & $0-4$ & 323 & 1.40 & .866 & \multirow{3}{*}{3.521} & \multirow{3}{*}{.030} \\
\hline & $5-14$ & 102 & 1.66 & 1.130 & & \\
\hline & $15 \&$ up & 24 & 1.71 & 1.367 & & \\
\hline \multirow{3}{*}{$\begin{array}{l}\text { Because of my life circumstances, I would not want } \\
\text { treatment }\end{array}$} & $0-4$ & 325 & 1.43 & .926 & \multirow{3}{*}{3.852} & \multirow{3}{*}{.022} \\
\hline & $5-14$ & 103 & 1.75 & 1.226 & & \\
\hline & $15 \&$ up & 24 & 1.54 & 1.103 & & \\
\hline \multirow{3}{*}{$\begin{array}{l}\text { Due to many other more important medical problems, I } \\
\text { would not want treatment }\end{array}$} & $0-4$ & 322 & 1.43 & .918 & \multirow{3}{*}{4.431} & \multirow{3}{*}{.012} \\
\hline & $5-14$ & 102 & 1.75 & 1.103 & & \\
\hline & 15 \& up & 23 & 1.57 & 1.199 & & \\
\hline \multirow{3}{*}{ I would discuss treatment with my family } & $0-4$ & 323 & 4.05 & 1.361 & \multirow{3}{*}{5.085} & \\
\hline & $5-14$ & 103 & 3.85 & 1.339 & & .007 \\
\hline & 15 \& up & 24 & 3.17 & 1.579 & & \\
\hline & $0-4$ & 324 & 4.31 & 1.142 & & \\
\hline I would take medication prescribed by my psychiatrist & $5-14$ & 102 & 4.15 & 1.189 & 3.208 & .041 \\
\hline & $15 \&$ up & 24 & 4.79 & .588 & & \\
\hline
\end{tabular}

${ }^{*}$ Scales 1-5, where 1 means strongly disagree, 2 means somewhat disagree, 3 means do not know, 4 means somewhat agree, and 5 means strongly agree. ${ }^{\dagger}$ ANOVA.

prescriptions or need to interact with a physician, enhancing the person's ability to self-manage their depression.

Perceptions regarding depression from older adults who are not depressed are also important because of their risk of developing depression later in life related to cardiovascular and cerebrovascular disease or other chronic diseases. This group may also have spouses suffering from depression, and their attitudes may impact the spouses' treatment. Caregivers' beliefs about the root of patient's depression can strongly influence medication adherence [28]. In a study examining adherence to lithium therapy for affective disorders, marriage was correlated with better adherence over a one-year period [29]. Marital status had a strong relationship with adherence to citalopram treatment in adults aged 60 years and older being seen in a primary care setting [30]. Additionally, those with poor marital support were more likely to have recurrent depressive symptoms and fail to comply with treatment one year after optimum medical therapy [31].

A striking correlate was found regarding the willingness to discuss treatment with family members. Greater depressive symptoms were associated with less conviction that a person would discuss treatment with family; however, there was a strong and consistent correlation with discussion of depression with family and willingness to accept all treatment options after accounting for all other variables. Paradoxically, those most in need of pursing treatment options for their 
TABLE 5: Multiple linear regression analyses on the treatment options.

\begin{tabular}{|c|c|c|c|}
\hline Predictors & Regression coefficient & $t$ value & $P$ value \\
\hline \multicolumn{4}{|l|}{ Meds from primary physician $\left(R^{2}=0.16\right)$} \\
\hline (i) History of depression & .34 & 2.64 & .0088 \\
\hline (ii) Depression needs to be treated & .22 & 2.61 & .0093 \\
\hline (iii) Depression is caused by one's life events & .11 & 2.08 & .0381 \\
\hline (iv) Discuss treatment with family & .18 & 4.18 & $<.0001$ \\
\hline (v) Depression improves without treatment & -.11 & -2.26 & .0247 \\
\hline (vi) Medications for depression would not help & -.13 & -2.17 & .0310 \\
\hline \multicolumn{4}{|l|}{ Meds from psychiatrist $\left(R^{2}=0.24\right)$} \\
\hline (i) Higher education & .22 & 2.25 & .0249 \\
\hline (ii) Depression needs to be treated & .22 & 2.65 & .0084 \\
\hline (iii) Depression is caused by one's life events & .12 & 2.36 & .0188 \\
\hline (iv) Discuss treatment with family & .19 & 4.63 & $<.0001$ \\
\hline (v) Depression is a personality trait & -.09 & -2.05 & .0413 \\
\hline (vi) Medications for depression would not help & -.27 & -4.68 & $<.0001$ \\
\hline \multicolumn{4}{|l|}{ Counseling $\left(R^{2}=0.23\right)$} \\
\hline (i) Higher education & .26 & 2.83 & .0049 \\
\hline (ii) Family does not agree with treatment & .16 & 2.44 & .0152 \\
\hline (iii) Discuss treatment with family & .21 & 5.45 & $<.0001$ \\
\hline (iv) Treatment for depression is embarrassing & -.17 & -3.60 & .0004 \\
\hline (v) I can control depression by myself & -.13 & -2.91 & .0039 \\
\hline (vi) Medications for depression would not help & -.17 & -2.94 & .0035 \\
\hline \multicolumn{4}{|l|}{ Follow MD's recommendations $\left(R^{2}=0.18\right)$} \\
\hline (i) Higher education & .26 & 3.08 & .0023 \\
\hline (ii) Discuss treatment with family & .20 & 5.73 & $<.0001$ \\
\hline (iii) Meds for depression would not help & -.22 & -4.59 & $<.0001$ \\
\hline \multicolumn{4}{|l|}{ Prayer and meditation $\left(R^{2}=0.29\right)$} \\
\hline (i) Religious belief & .76 & 11.38 & $<.0001$ \\
\hline (ii) Discuss treatment with family & .18 & 3.80 & .0002 \\
\hline (iii) Pay health expenses with my earnings & -.37 & -2.63 & .0088 \\
\hline \multicolumn{4}{|l|}{ Use herbs or supplements $\left(R^{2}=0.10\right)$} \\
\hline (i) Can control depression by myself & .19 & 3.46 & .0006 \\
\hline (ii) Discuss treatment with family & .14 & 2.73 & .0066 \\
\hline (iii) Older age & -.03 & -3.48 & .0006 \\
\hline (iv) Higher education & -.37 & -3.01 & .0028 \\
\hline \multicolumn{4}{|l|}{ Increase alcohol intake $\left(R^{2}=0.14\right)$} \\
\hline (i) Due to life circumstances, I do not want treatment & .11 & 2.45 & .0149 \\
\hline (ii) Medications for depression would not help & .09 & 2.12 & .0347 \\
\hline (iii) Discuss treatment with family & -.10 & -3.41 & .0007 \\
\hline (iv) Pay health expenses from my earnings & -.21 & -2.62 & .0092 \\
\hline (v) Religious belief & -.14 & -3.43 & .0007 \\
\hline
\end{tabular}

mood may be the very people least willing to discuss treatment with their loved ones, leading to poorer outcomes and undue suffering. This finding is consistent with the use of psychoeducational workshops for depressed patients and their families to promote continuation treatment for the depressed patients [32]. The willingness to discuss treatment options with family is a condition associated with enhanced acceptance of medication use, counseling, and following the doctor's recommendations. Encouraging patients to have a family member accompany them to office visits is one approach to enhance family communications regarding the importance of symptom monitoring and treatment compliance.

Our sample was insured, lived in an area with accessible mental health resources, and did not report cost as a barrier to depression treatment. The most common reason for not seeking mental health treatment in a sample of 6,510 adults was concern about costs [33]. Significant proportions (19\% to $38 \%$ ) of elderly subjects with depressive symptoms report cost-related nonadherence to medications [34]. Differing 
healthcare plans have been linked to poor mental health followup [35] and have been shown to impact access to antidepressant medication management and other treatment options [36]. Counseling services are highly variable among private and state-run health insurances and dependent on local access and availability of qualified mental health professionals, which may also explain some of the variation in our results locally and on a national level. Further research is needed to assess the impact of insurance coverage on the acceptance of treatments for depression.

Several potential clinical implications arise from this exploratory study. Screening for depression in primary care settings is acceptable to older patients. Attitudes of patients and their circumstances may help predict the acceptability of and compliance with depression treatments. Attitudes should be queried after making the diagnosis and before prescribing treatments. This is similar to the recommendation made following the study of younger depressed primary care patients in the United Kingdom [21]. Family involvement in treatment is an enhancing factor in treatment acceptability. Offering to discuss depression and treatment options with both patient and family may help improve compliance and treatment outcomes.

There are several limitations to the study, including generalizability and power to detect significant findings in the smaller depressed sample. The study sample was mainly drawn from an academic primary care setting and may not represent the general older, ambulatory population. Although 50 percent of the sample had a college education and less than one percent had no insurance, characteristics such as number and kinds of chronic diseases, general health ratings, and other demographic variables were similar to the general older population.

To overcome these limitations, a similar study needs to be conducted with a larger sample size, preferably in a primary care research network. If attitudinal factors are related to treatment acceptability, a screening of attitudes towards depression should be used in an intervention trial. Physicians do inquire about the acceptability of treatments before prescribing, but better understanding of the patients' and families' beliefs may help determine the extent of education needed for any individual patient. If a strong relationship between family involvement and treatment acceptance is confirmed, a comparison trial between usual care and a family intervention trial would be of value, with the outcome variables of remission of depression and compliance with continuation treatment.

\section{Conclusions}

It is important to understand the patients' perceptions regarding depression, as well as other enhancers or barriers to effective treatment. Patients believe that depression is a disease that requires treatment and that physicians should ask their patients about depressive symptoms. The willingness to discuss depression with family appears to be associated with greater acceptance of depression treatments. Physicians' facilitation of these family discussions may be an effective approach to increase treatment compliance and improve depression outcomes.

\section{Conflict of Interests}

None of the authors have any conflict of interests to disclose.

\section{Acknowledgment}

Funding for this study was provided by Dr. Richard O. Emmons Memorial Fund, University of Iowa Foundation, which had no involvement in the study design; collection, analysis, or interpretation of data; the writing of the paper; or the decision to submit the paper for publication.

\section{References}

[1] M. Luppa, T. Luck, H. Konig, M. Angermeyer, and S. RiedelHeller, "Natural course of depressive symptoms in late life an 8-year population-based prospective study," Journal of Affective Disorders, vol. 142, pp. 166-171, 2012.

[2] D. G. Blazer, "Depression in late life: review and commentary," Journals of Gerontology A, vol. 58, no. 3, pp. M249-M265, 2003.

[3] S.-M. Lai, P. W. Duncan, J. Keighley, and D. Johnson, "Depressive symptoms and independence in BADL and IADL," Journal of Rehabilitation Research and Development, vol. 39, no. 5, pp. 589-596, 2002.

[4] G. S. Alexopoulos, "Depression in the elderly," The Lancet, vol. 365, no. 9475, pp. 1961-1970, 2005.

[5] B. Ravina, R. Camicioli, P. G. Como et al., "The impact of depressive symptoms in early Parkinson disease," Neurology, vol. 69, no. 4, pp. 342-347, 2007.

[6] E. Licht-Strunk, H. W. van Marwijk, T. Hoekstra, J. W. Twisk, M. de Haan, and A. T. Beekman, "Outcome of depression in later life in primary care: longitudinal cohort study with three years' follow-up," British Medical Journal, vol. 338, p. a3079, 2009.

[7] E. A. Bayliss, J. L. Ellis, and J. F. Steiner, "Barriers to selfmanagement and quality-of-life outcomes in seniors with multimorbidities," Annals of Family Medicine, vol. 5, no. 5, pp. 395402, 2007.

[8] D. R. Royall, J. E. Schillerstrom, P. K. Piper, and L. K. Chiodo, "Depression and mortality in elders referred for geriatric psychiatry consultation," Journal of the American Medical Directors Association, vol. 8, no. 5, pp. 318-321, 2007.

[9] E. Scafato, L. Galluzzo, S. Ghirini et al., "Changes in severity of depressive symptoms and mortality: the Italian Longitudinal Study on aging," Psychological Medicine, vol. 42, no. 12, pp. 26192629, 2012.

[10] M. L. Bruce, T. R. Ten Have, C. F. Reynolds III et al., "Reducing suicidal ideation and depressive symptoms in depressed older primary care patients: a randomized controlled trial," Journal of the American Medical Association, vol. 291, no. 9, pp. 1081-1091, 2004.

[11] J. Unützer, W. Katon, C. M. Callahan et al., "Collaborative care management of late-life depression in the primary care setting: a randomized controlled trial," Journal of the American Medical Association, vol. 288, no. 22, pp. 2836-2845, 2002.

[12] H. C. Driscoll, J. F. Karp, M. A. Dew, and C. F. Reynolds III, "Getting better, getting well: understanding and managing 
partial and non-response to pharmacological treatment of nonpsychotic major depression in old age," Drugs and Aging, vol. 24, no. 10, pp. 801-814, 2007.

[13] C. F. Reynolds III, M. A. Dew, B. G. Pollock et al., "Maintenance treatment of major depression in old age," New England Journal of Medicine, vol. 354, no. 11, pp. 1130-1138, 2006.

[14] R. Maidment, G. Livingston, and C. Katona, “Just keep taking the tablets': adherence to antidepressant treatment in older people in primary care," International Journal of Geriatric Psychiatry, vol. 17, no. 8, pp. 752-757, 2002.

[15] H. B. Bosworth, C. I. Voils, G. G. Potter, and D. C. Steffens, "The effects of antidepressant medication adherence as well as psychosocial and clinical factors on depression outcomeamong older adults," International Journal of Geriatric Psychiatry, vol. 23, no. 2, pp. 129-134, 2008.

[16] K. Zivin and H. C. Kale, "Adherence to depression treatment in older adults: a narrative review," Drugs and Aging, vol. 25, no. 7, pp. 559-571, 2008.

[17] J. Srinivasan, N. L. Cohen, and S. V. Parikh, "Patient attitudes regarding causes of depression: implications for psychoeducation," Canadian Journal of Psychiatry, vol. 48, no. 7, pp. 493-495, 2003.

[18] J. L. Givens, C. J. Datto, K. Ruckdeschel et al., "Older patients' aversion to antidepressants: a qualitative study," Journal of General Internal Medicine, vol. 21, no. 2, pp. 146-151, 2006.

[19] D. G. Blazer, "How do you feel about...? Health outcomes in late life and self-perceptions of health and well-being," Gerontologist, vol. 48, no. 4, pp. 415-422, 2008.

[20] J. A. Sirey, M. L. Bruce, G. S. Alexopoulos et al., "Perceived stigma as a predictor of treatment discontinuation in young and older outpatients with depression," American Journal of Psychiatry, vol. 158, no. 3, pp. 479-481, 2001.

[21] S. Weich, L. Morgan, M. King, and I. Nazareth, "Attitudes to depression and its treatment in primary care," Psychological Medicine, vol. 37, no. 9, pp. 1239-1248, 2007.

[22] R. L. Spitzer, K. Kroenke, J. B. W. Williams, and the Patient Health Questionnaire Primary Care Study Group, "Validation and utility of a self-report version of PRIME-MD: the PHQ Primary Care Study," Journal of the American Medical Association, vol. 282, no. 18, pp. 1737-1744, 1999.

[23] B. Löwe, J. Unützer, C. M. Callahan, A. J. Perkins, and K. Kroenke, "Monitoring depression treatment outcomes with the patient health questionnaire-9," Medical Care, vol. 42, no. 12, pp. 1194-1201, 2004.

[24] C. S. Mackenzie, T. Scott, A. Mather, and J. Sareen, "Older adults help-seeking attitudes and treatment beliefs concerning mental health problems," American Journal of Geriatric Psychiatry, vol. 16, no. 12, pp. 1010-1019, 2008.

[25] M. A. Prins, P. F. M. Verhaak, J. M. Bensing, and K. van der Meer, "Health beliefs and perceived need for mental health care of anxiety and depression-The patients' perspective explored," Clinical Psychology Review, vol. 28, no. 6, pp. 1038-1058, 2008.

[26] A. M. Gum, P. A. Areán, E. Hunkeler et al., "Depression treatment preferences in older primary care patients," Gerontologist, vol. 46, no. 1, pp. 14-22, 2006.

[27] V. A. Benassi, P. D. Sweeney, and C. L. Dufour, "Is there a relation between locus of control orientation and depression?" Journal of Abnormal Psychology, vol. 97, no. 3, pp. 357-367, 1988.

[28] S. T. Bogardus Jr., E. H. Bradley, C. S. Williams, P. K. Maciejewski, W. T. Gallo, and S. K. Inouye, "Achieving goals in geriatric assessment: role of caregiver agreement and adherence to recommendations," Journal of the American Geriatrics Society, vol. 52, no. 1, pp. 99-105, 2004.

[29] C. E. Connelly, Y. B. Davenport, and J. I. Nurnberger Jr., "Adherence to treatment regimen in a lithium carbonate clinic," Archives of General Psychiatry, vol. 39, no. 5, pp. 585-588, 1982.

[30] H. R. Bogner, J. Y. Lin, and K. H. Morales, "Patterns of early adherence to the antidepressant citalopram among older primary care patients: the prospect study," International Journal of Psychiatry in Medicine, vol. 36, no. 1, pp. 103-119, 2006.

[31] F. W. Reimherr, R. E. Strong, B. K. Marchant, D. W. Hedges, and P. H. Wender, "Factors affecting return of symptoms 1 year after treatment in a 62-week controlled study of fluoxetine in major depression," Journal of Clinical Psychiatry, vol. 62, no. 21, pp. 1623, 2001.

[32] J. T. Sherrill, E. Frank, M. Geary, J. A. Stack, and C. F. Reynolds III, "Psychoeducational workshops for elderly patients with recurrent major depression and their families," Psychiatric Services, vol. 48, no. 1, pp. 76-81, 1997.

[33] R. Mojtabai, "Unmet need for treatment of major depression in the United States," Psychiatric Services, vol. 60, no. 3, pp. 297305, 2009.

[34] K. Z. Bambauer, D. G. Safran, D. Ross-Degnan et al., "Depression and cost-related medication nonadherence in medicare beneficiaries," Archives of General Psychiatry, vol. 64, no. 5, pp. 602-608, 2007.

[35] S. F. Greenfield, J. M. Reizes, L. R. Muenz, B. Kopans, R. C. Kozloff, and D. G. Jacobs, "Treatment for depression following the 1996 national depression screening day," American Journal of Psychiatry, vol. 157, no. 11, pp. 1867-1869, 2000.

[36] C. M. Horgan, E. L. Merrick, M. T. Stewart, S. H. Scholle, and S. Shih, "Improving medication management of depression in health plans," Psychiatric Services, vol. 59, no. 1, pp. 72-77, 2008. 


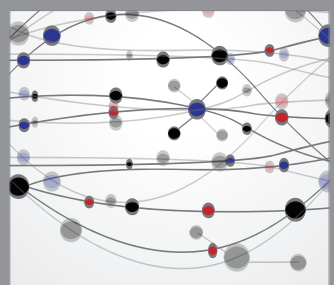

The Scientific World Journal
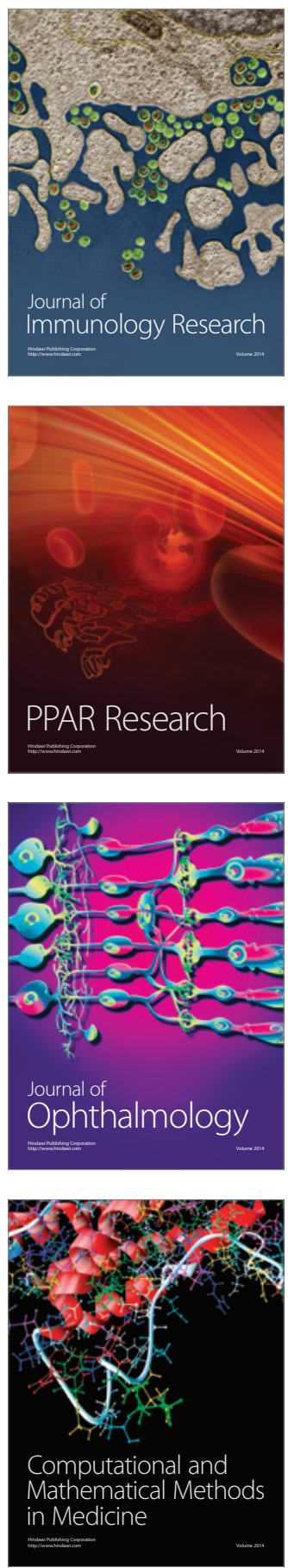

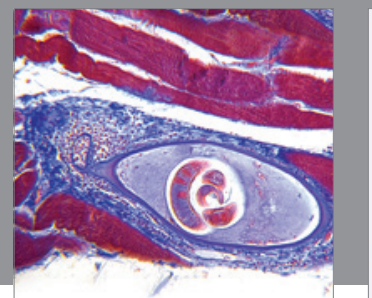

Gastroenterology

Research and Practice
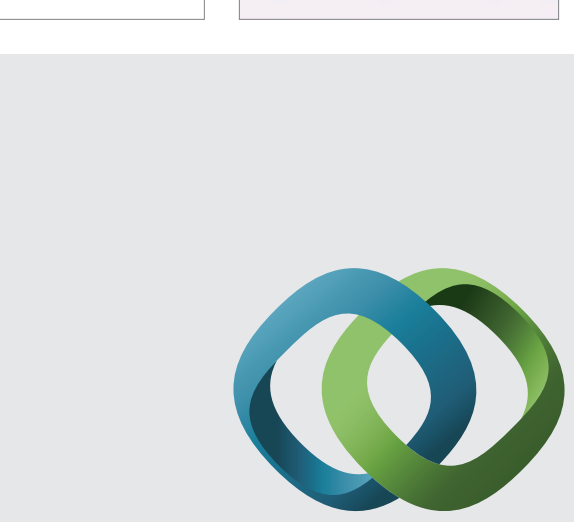

\section{Hindawi}

Submit your manuscripts at

http://www.hindawi.com
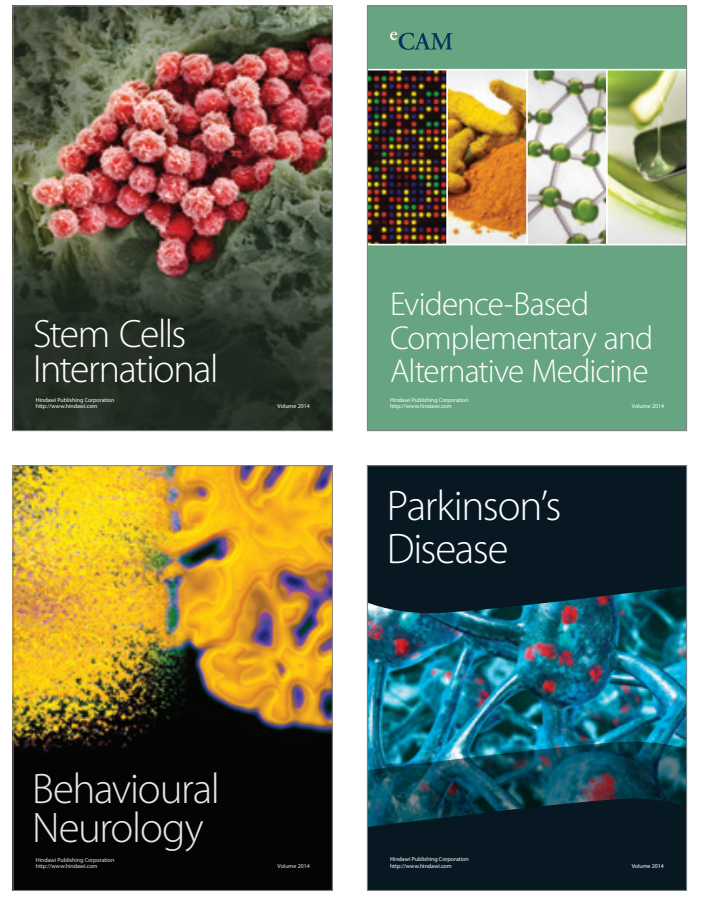
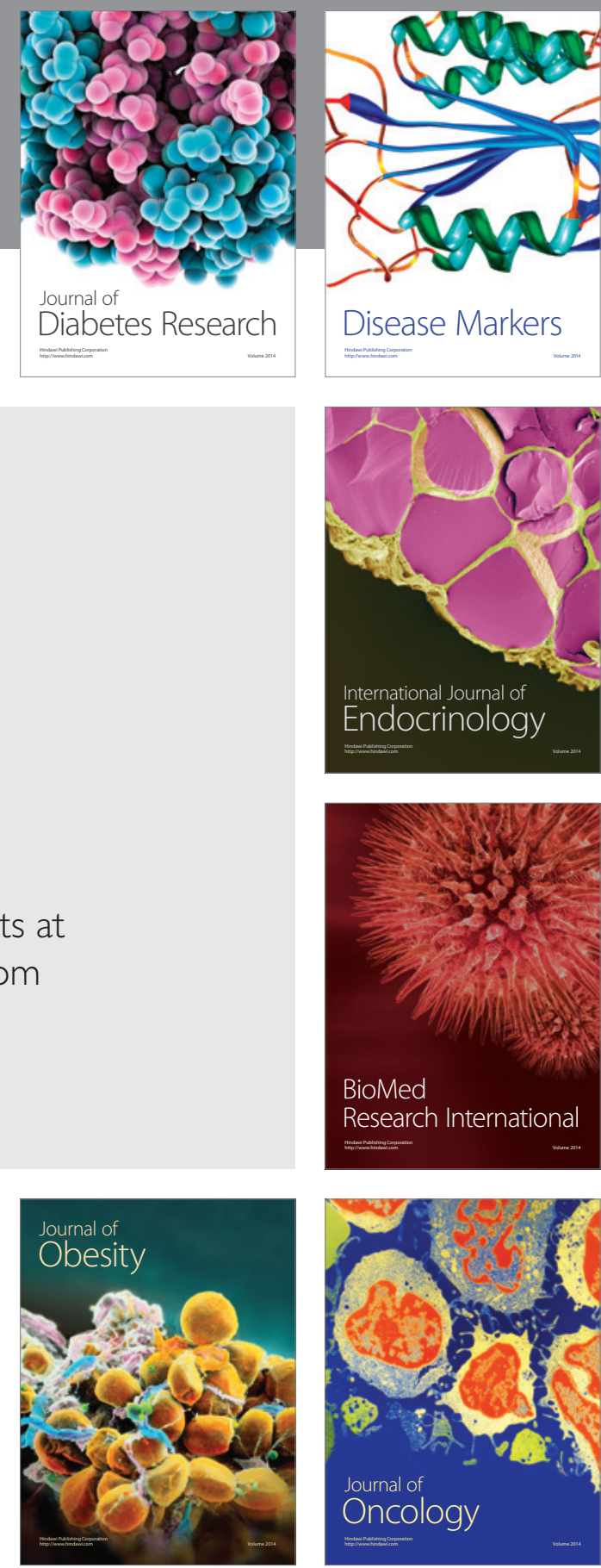

Disease Markers
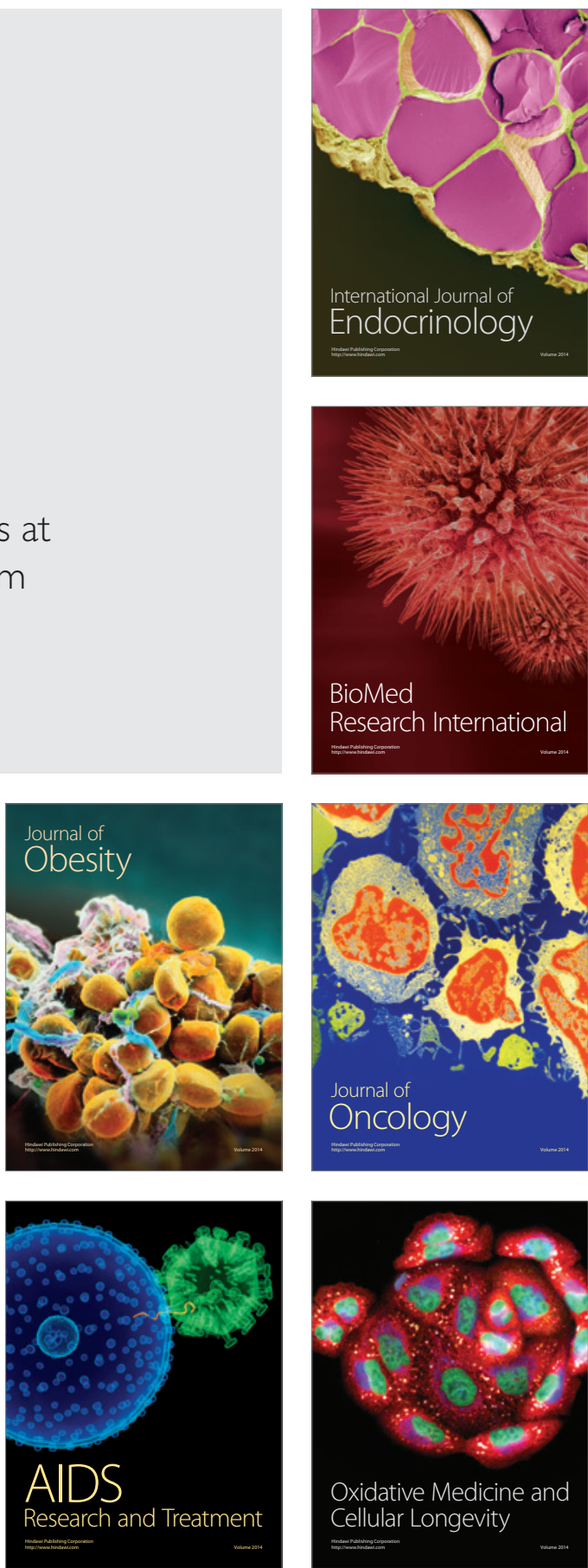